\title{
We are all migrants
}

\author{
Jaan Valsiner ${ }^{*}(\mathbb{D}$
}

${ }^{*}$ Correspondence:

jvalsiner@valsiner.org

Centre of Cultural

Psychology, Aalborg

University, Aalborg, Denmark

\begin{abstract}
Migration is the basis for development-economic, social, and psychological. In this paper I will examine borders on migration that entail the ambivalent relating by the societal context of migration to the act of movement of the people who become migrants, and their counterparts ("counter-migrants") who do not. My focus on the issue stems from my theory of Cultural Psychology of Semiotic Dynamics that can deal with the process of becoming, being, and feeling as "migrant" or "counter-migrant". A societal rule system is fortified by the system of social representations of the people who-by the act of moving from one place to another-are designated to become migrants by the rule systems of the non-migrants. Cultural psychology contributes to the study of the emerging prejudices and ways of their overcoming by the nonmigrant local recipients as well as to the ambivalences of the persons who move to the relating with the social role "migrant" and its overcoming. Historically speaking - we as the species of Homo sapiens are all migrants — only at differing times and circumstances.
\end{abstract}

Keywords: Migration, Prejudice, Social role, Ambivalence, Strength, Meaning making

Where is the border between moving around and migration? Is there such border at all-despite the desires of migration researchers to resist over-inflating the meaning of the term that defines their research object? Children's going to school and their parents going to work every day is regular movement from one place to another, and back, but there is scarcely any reason to study these movements as migrations. Or maybe there is-but our borders of scientific constructions of what is important for science have left such phenomena homeless in the field of migration research.

Coming into the field of interdisciplinary efforts to understand migration from the perspective of my Cultural Psychology of Semiotic Dynamics I would try to make sense of migration starting from the irreversible movement of the meaning making by our constructive minds. This entails no difference between "internal migration" (a person feeling left out in all matters of society, wanting-and finding a hideout for herself in the depths of the mind, without moving physically to anywhere) and "external migration"-leaving behind one's native village, possibly for good, and establishing oneself in an environment dramatically different from the original place. The exodus of early Christian monks to live in isolated caves in Egyptian Desert is a unification of the internal and external forms of migration. The place arrived may be not easy to live in, but the

(c) The Author(s), 2022. Open Access This article is licensed under a Creative Commons Attribution 4.0 International License, which permits use, sharing, adaptation, distribution and reproduction in any medium or format, as long as you give appropriate credit to the original author(s) and the source, provide a link to the Creative Commons licence, and indicate if changes were made. The images or other third party material in this article are included in the article's Creative Commons licence, unless indicated otherwise in a credit line to the material. If material is not included in the article's Creative Commons licence and your intended use is not permitted by statutory regulation or exceeds the permitted use, you will need to obtain permission directly from the copyright holder. To view a copy of this licence, visit http:// creativecommons.org/licenses/by/4.0/. 


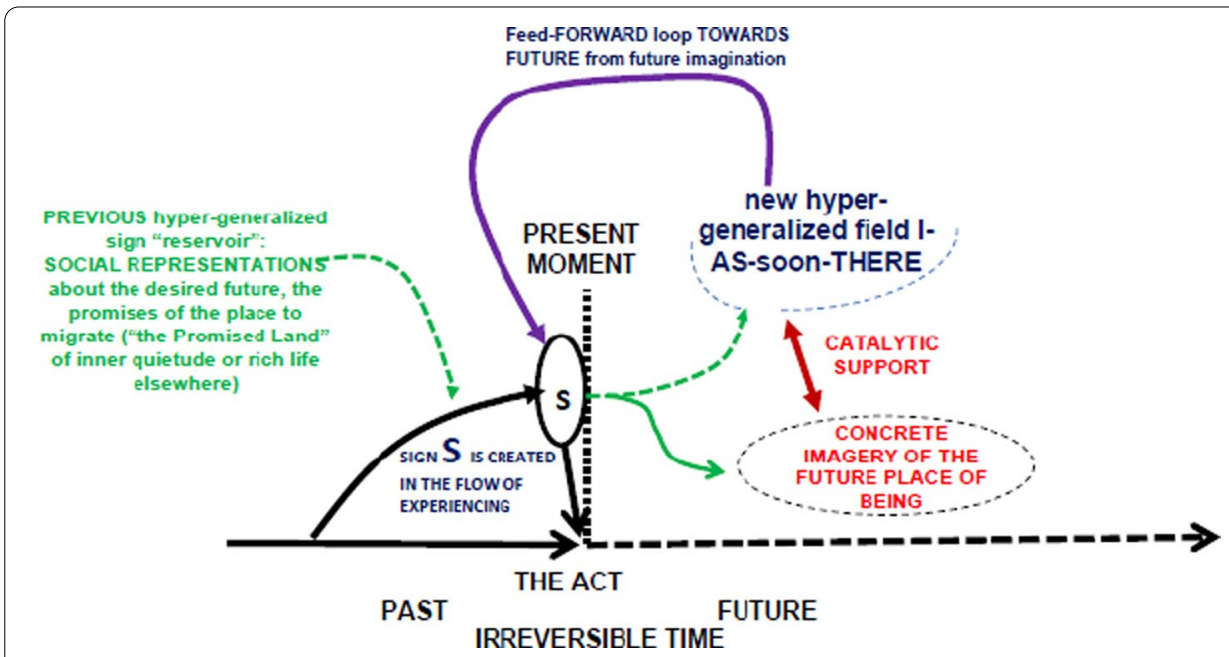

Fig. 1 The feed-forward loop of meaning making in migration

intentionality of the move compensates for it As children of Kochin Jewish emigrees to a small kibbutz near Beer Sheva in the 1950s asked their parents- "is this desert really the Promised Land you said we come to?". But there was no way back to the rich greenery of Southern India.

What unites the two opposites-"internal" and "external"-is the personal construction of the life course. Particular circumstances are always person-specific, but the general scheme of meaning construction is the same- intentionally directed construction of meaning here-and-now, in the service of the future there-and-then (Fig. 1). In contrast to the regular semiotic mediation where the sign in the Present dominates over its future role as a hyper-generalized catalyst, in migration it is the future imaginary meaning that gives flavour to the meanings in the present. That imagery is double-hyper-generalized feeling field of "being there", and concrete imagination of the place one expects to be in.

Figure 1 illustrates the need for a migrating person to generate non-realistic images of the future-catalyzed by the hyper-generalized field of feeling-into-future. The second important feature in Fig. 1 is the feedforward loop from future imaginary feeling to the present striving towards the actualization of the future place.

The focus on catalysis-relevance of factors that are needed to be present but do not have causal roles-is standard in chemistry for almost two centuries. It is time to bring that concept to the social sciences. Needless to add here that the catalytic support between the two imageries of the future-the hyper-generalized and the concreteconstitute a redundant system where only one of the parts is sufficient to drive the present meaningfulness of the act. A migrant desiring to reach New York City in early 1900s could observe the panorama from the distance of the Ellis Island primitive holding camp, still fascinated by the freedom soon to be experienced. Another migrant may have sufficient support from the hyper-generalized feeling and an undifferentiated image of the place where one would be. These images can be supported by painted images of the primary migration targets-Heaven, Hell, and Purgatory-in the European migration history. In the love-oriented eighteenth century the migration would be imagined to happen to Cythera-the imagined Island of Love (Fig. 2). 


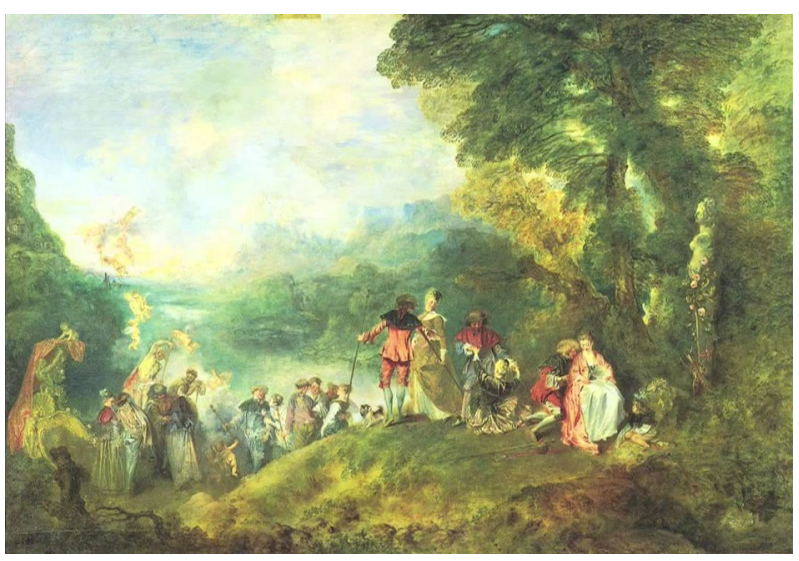

Fig. 2 Embarkation to Cythera (Jean-Antoine Watteau, 1717)

Migrants also look for love- in its many manifestations. Their imagination is heightened to the level of multiple imaginings of the future.

\section{The importance of redundant imagination}

The two levels of future-oriented catalytic imagination in Fig. 1 are relevant as they create the redundant control system for the present effort to move towards the migration state. Very often one can hear exaggerated myth-stories of all the positive images of the migration target place ("once we get to Europe - or to California-we will be X!"). Such exaggerations are important - even if usually illusory - feed-forward motivators in the present state of affairs.

I myself am a migrant. On January, 13, 1980 I witnessed the panorama of my home town disappear into the icy darkness as I was looking back to the reality of my own life and the impending change in it as I felt I would never see my home country again. The feeling was overwhelming-I had no idea where I could end up, but enormous determination to find my place somewhere in the World. Stories of "rich living" in the countries I was to live in did not appeal to me, but the need for free space of creation did. What followed were decades of further migration-through ideas, places, and societal conditions. Even in place for four decades (physically) I am still a migrant in the depth of my mind. And happy about it-development without migration would be impossible. Returns to my native land tell me a story of deep identity that is not linked with any external form of identification. A migrant develops beyond one's roots-even if appreciating the latter.

\section{Migrants and counter-migrants}

Migration needs a frame-a background system that allows us to make sense of the specific phenomena linked with migration per se. Migrants as actors are detectable in their movements in contrast to non-migrants-or counter-migrants. These are persons 


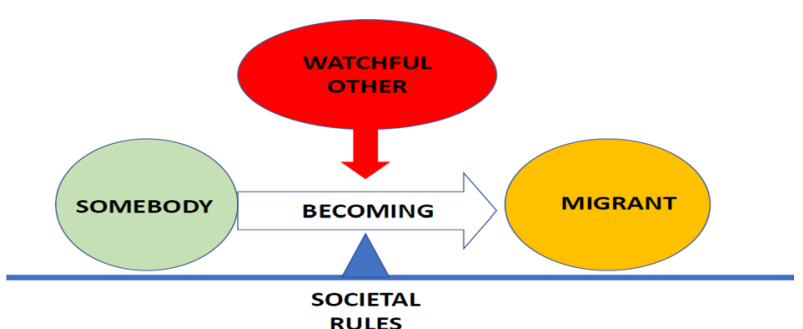

RULES

Fig. 3 The simple system of migrants and counter-migrants

who-themselves results of migration over centuries or millenia ${ }^{1}$ - have become settled in their particular places and have become apprehensive about others who move in, or past, their established ways of living. Furthermore-the role of counter-migrant can be a dialogic partner for the migrant in the depth of one's mind. In my personal story told above, I would need to add that the miraculous success of getting out of the then Soviet Union was preceded by about two years of deep depression and doubting between the internal voices of "migrant" and "counter-migrant". The internal dialogue was harshleading to tears of desperation-until a possible opening in the "Iron Curtain" appeared on the horizon.

The framework of Migrant<> Counter-Migrant unified system is depicted in Fig. 3. Here we have a very simple-and most migration events are simple-process structure. Somebody sets oneself onto the move towards some other place without the reverse move. The MIGRANT emerges. Together with that emerge the roles of CounterMIGRANTs - the "watchful others" who-maintaining the stability of the given stationary community-carefully observe the migration process. This observation is affect-driven (ranging from positive "here we have new possibilities" to negative "we cannot let these migrants live like us here") and regulated by social and legal norm systems. The latter may call for help for the migrants by the counter-migrants-setting up a moral dilemma of deeply ambivalent kind.

The ambivalences of Counter-Migrants are probably the major root for viewing the processes of migration as a social issue. The conditions where the Counter-Migrants function is not present-such as relatives moving to join their other relatives in a place far away, being welcomed to the family-are not presentable as social problems. It is the Unknown Otherness of the migrants that triggers the ambivalence of the CounterMigrants. They may in words welcome the "refugees" and then do their utmost that these welcomed people be settled far from them. Or-at the governmental level-when Syrian refugees started to walk towards Scandinavia to escape the civil war, the Danish government sent leaflets to Syria warning the refugees not to want to come to Denmark. They ended walking through to Sweden where they were more positively accepted.

There is a lesson here to be learned for research on migration - who are the objects of investigation if we want to understand migration? From what I claim here the primary

\footnotetext{
${ }^{1}$ By analysis of genetic haplotypes all human beings come from East Africa and are thus migrants. In their process of migration they have lost their original skin color-black-and have developed into a wide variety of human forms most established in sedentary conditions. So, the current political slogan "Black lives matter!" has deep historical meaningwithout Black migrants of 80,000 years ago we would not exist. Independent of our present state-we are all Black! It is only interesting that the depictions of expelling the first human beings-Adam and Eve-are faulty painting them white.
} 
objects would be Counter-Migrants-they are the ones who create the "migrant situation" by their apprehension of the Migrants who either move in or walk by. This point is at least slightly counter-intuitive-yet in the way the phenomenon emerges for the social sciences it is precisely so. The study of migrants out of the context of relating with Counter-Migrants would give us no key to the issue at large. ${ }^{2}$

How can I prove my point? Consider a whole community living in place $\mathrm{X}$ that decides to relocate to place $\mathrm{Y}$ which is not inhabited by anybody, and make their permanent home there. They make the move, re-establish themselves in the new place, and stay. They have migrated-but there are no Counter-Migrants around-at least of the external kind (internally it may be different-refer back to theKochin-BeerSheeva example above). The community would net be viewed as creating a "migration problem", but is simply that of a re-settlement. There is migration-but no "migration problem" that could worry politicians and social scientists.

Now-if this hypothetical scenario is made more complex and we find another community already living on the re-settlement site-the "migration problem" as a social problem immediately ensues. The "problem" is a result of encounter-and of competition for resources in the local context. Figure 3 is now the fitting presentation-the re-settlers become Migrants as they are observed and related with by the CounterMigrants. The social frictions that emerge-illusory or real-mark the making of the "migration problem". Without the Counter-Migrants none of this could happen.

\section{Conclusion: The "migration problem" in the social sciences is the problem of fluid borders}

An interdisciplinary effort to make sense of migration needs to involve explanatory systems of the level of abstraction that transcend all ideologically flavored perspectives on the target issue. The hypothetical example above leads us to the formal conclusion-migration is an issue of flexible fluid borders in the relation between Migrants and Counter-Migrants. The border can by internal in the person's mind, or external on the division lines protected by border police and barbed wire fences on political country limits. In the latter case the migrants climb under, or over, build tunnels under or fly on balloons to get to the other side. Openings in the closed borders are somewhere.

The notion of borders in cultural psychology emulates that of membranes in biology. Membranes are crucial for the work of multi-cellular organisms precisely because they both block and allow transfer of substances between cells. This double function of the membrane transfer mechanisms is crucial for life. And these mechanisms can be complex-catering both for opening and closing of the trans-membrane channels. Where are these mechanisms in the migration research-if done within the Cultural Psychology of Semiotic Dynamics? Here each of the "trans-membranal channel" is built up as a hierarchy of signs, while the border itself remains invisible. Most borders in our psychological and social lives are of that kind-themselves invisible, but the locations where they are being crossed-increasingly evident.

\footnotetext{
${ }^{2}$ This is not meant to denigrate the value of the knowledge of migration experience-hardships in transition, difficulties in crossing borders, frustrations, lack of resources, suspicions by locals, etc. Yet these are hardships of any long-term move from one place to another, for different reasons (e.g. pilgrimage). These features are not specific for migration as such.
} 


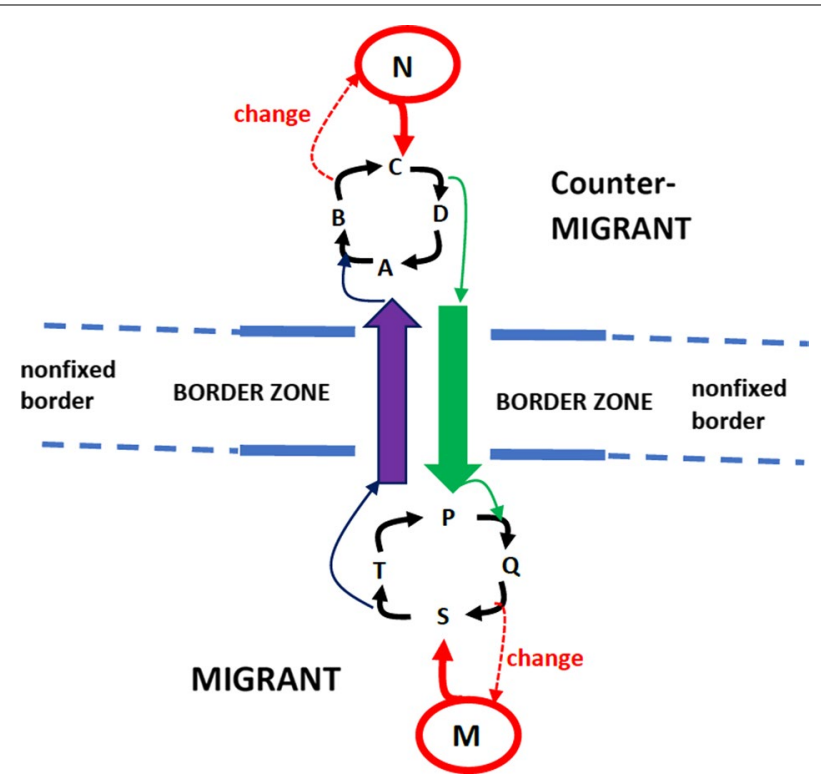

Fig. 4 The process of negotiation of the Migrant $<>$ Counter relations on the border locus

The hierarchy of signs is always dynamic and open to its own transformation. This makes the actions of a Counter-Migrant in relation to (real or imaginary) Migrant inherently ambivalent and rapidly moving from positive to negative relations, and back.

Figure 4 provides a simplified example of the border-crossing mechanisms. The border between the Migrant and Counter-Migrant is set up on the locus of a particular encounter-mutual rivalry for jobs, welcoming the migrants to the local community, occasional meeting in the street, etc. The border is a here-and-now local phenomenon- episodic, uncertain, and transitory. The particular transitory zone in the border is organized by the hierarchical sign organization on both sides-for the Migrant (P-Q-S-T...M) and for the Counter-Migrant (A-B-C-D...N) where cycles of signs can become subordinated to the general organizers $(\mathrm{M}, \mathrm{N})$ of the meaning construction systems. $\mathrm{M}$ and $\mathrm{N}$ need not be in action in the usual flow of meaning construction of the Other, but can be activated under conditions where re-organization of the meaning system is needed.

As an example, let us fill in the meanings in the two cycles in Fig. 4 with specific ranges of meanings:

$\mathrm{A}(\mathrm{P})=$ "I am \{positive $<>$ non-positive $\}$ towards fellow human beings"

$\mathrm{B}(\mathrm{Q})=$ "I \{recognize $<>$ non-recognize this person as a fellow human being"

$\mathrm{C}(\mathrm{S})=$ "I feel we must $\{$ help $<>$ non-help\} fellow human beings"

$\mathrm{D}(\mathrm{T})=$ "I feel \{positive $<>$ non-positive $\}$ about my $\{$ help $<>$ non-help\} to fellow human being"

Each meaning is accompanied by its counter-meaning ( $\mathrm{X}$ and non- $\mathrm{X}$ ). The movement between these opposites depends on the meta-level regulatory signs $(\mathrm{M}, \mathrm{N})$ that can re-orient the cycle below from the positive to the negative domain.

In a more specific-still hypothetical-an example a Migrant arrives into the community of Counter-Migrants and is heartily welcome. The Counter-Migrants- 
individually and collectively-recognize her or him as a fellow human being (equal in rights to them-rather than a category of non-equal status-such as a slave, or an enemy). The Migrant gets all kinds of needed help from the community, and the Counter-Migrants in the community praise themselves and one another for their humane help to the Migrant. The Migrant is-correspondingly-appreciative of the help and is ready to contribute to the community.

However, "contribution to community" is an inherently ambiguous notion. It includes everything from conforming to the present community status quo, to various acts of innovation that would change the existing ways of being. The Migrant brings to the community new ways of thinking and implements these. By doing that she or he becomes suspicious for the community ( $\mathrm{B} \rightarrow \mathrm{C}$ "I recognize him-her as a competitor and do not want to help") together with change in the superordinate meaning field $\mathrm{N}$. The Counter-Migrant meaning cycle now moves to the non-X domain resulting in suspicion, discrimination, and also anti-Migrant acts of violence. The Migrant side need not recognize that ("I am trying my best to bring my skills to the community"), or-if M becomes correspondingly changed to the non-positive side- develops a parallel opposition to the new Counter-Migrant meaning cycle. The result is complete break of trust between the two, mutual suspicions, and mutual violent attacks. Societal change is a sensitive process where outsiders' (Migrants') role can be deeply ambivalent in how social change can be brought about. Figure 4 shows how various versions of "contact utopias"-bring two ethic groups to contact and they melt into a new society-need not work on the border encounters of Migrants and Counter-Migrants.

What would this kind of argumentation mean for the research practices of migration. The scenario is rather clear-first of all, the focus on the study is on the Counter-Migrants who create the social conditions for Migrants. Secondly-the dynamics of meaning making within the same Counter-Migrant-covering the whole range of the meaning fields. Here all actions-from generous help to the Other to discrimination and stigmatization of the same Other-are covered by the same general process mechanisms of semiotic dynamics.

Finally-it is obvious that migration is central for all development-economic, social, psychological. An imaginary scenario of no migration-with only various independent communities of Counter-Migrants existing side by side, not relating to one another, would give us a set of closed systems that would necessarily deteriorate. That this is not happening is guaranteed by the minimal migration tradition - that of exogamy that modifies by necessity the family lives in these different communities. We will always be migrants - and that keeps our societies alive.

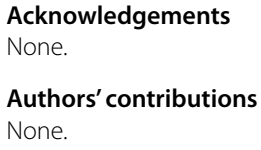


Funding

None.

Availability of data and materials

Not applicable.

\section{Declarations}

Competing interests

The author declares no competing interests.

Received: 15 July 2021 Accepted: 10 December 2021

Published online: 13 January 2022

\section{Publisher's Note}

Springer Nature remains neutral with regard to jurisdictional claims in published maps and institutional affiliations.

Submit your manuscript to a SpringerOpen ${ }^{\circ}$ journal and benefit from:

- Convenient online submission

- Rigorous peer review

- Open access: articles freely available online

- High visibility within the field

Retaining the copyright to your article

Submit your next manuscript at $\boldsymbol{\Delta}$ springeropen.com 